\title{
Analysis of bimetal pipe bends with a bend of 0.7D with a cladding layer of Inconel 625
}

Martin Slany ( $\nabla$ slany.m@fme.vutbr.cz )

Brno University of Technology: Vysoke uceni technicke v Brne https://orcid.org/0000-0002-9162-0066 Josef Sedlak

Jan Zouhar

Oskar Zemcik

Karel Kouřil

Aleš Polzer

Zdenek Pokorny

Zdenek Joska

David Dobrocky

Zbynek Studeny

\section{Research Article}

Keywords: Bimetal pipes, Pipe bend, Steel 16Mo3, Inconel 625, cladding

Posted Date: February 23rd, 2021

DOl: https://doi.org/10.21203/rs.3.rs-223009/v1

License: (a) This work is licensed under a Creative Commons Attribution 4.0 International License. Read Full License 


\section{Abstract}

Bimetal pipes are highly stressed composite components that must resist corrosion in a chemically aggressive environment. The production of pipe bends with a supercritical bend of $0.7 D$, which form the part of serpentine systems, is very complex and technologically demanding, because very often undesired cracks occur. To increase the service life of these serpentine systems, the use of a $16 \mathrm{Mo} 3$ base steel pipe with a cladding layer of Inconel 625 material was proposed for their production in order to significantly increase their corrosion resistance. For this reason, an extensive analysis of the production of pipe bends with a supercritical bend of 0.7D from bimetal pipes with Inconel 625 cladding was performed, which addressed not only the bend but also the mechanical properties of the pipe with Inconel 625 cladding. It was found out that the production of the pipe bend with a bend of 0.7D of a bimetal pipe is feasible completely without defects with perfectly satisfactory mechanical properties.

\section{Introduction}

Bimetalpipes are composite components that use the strength of carbon steel to withstand high pressures, and the second cladded material gives them corrosion resistance in their chemically aggressive working environment. They are irreplaceable in many industries, being used to transport oil, gas, salt water or steam, or in the energy industry in waste incinerators $[1,2]$.

The pipe bend is a straight pipe bent into the required shape, which is used in the so-called serpentine system for plate superheaters and economizers, which form pipe bundles for partial parts of boilers. The whole serpentine system consists of straight pipes, on which $180^{\circ}$ pipe bends with extended ends with a bend of 1D and 0.7D are cladded [3]. Due to its affordability, a 16Mo3 steel pipe is commonly used, according to the European standard EN 10028-2 [4], which ensures good mechanical properties, but has a service life of approximately 6 months. After the degradation of the pipe material, the device must be shut down, dismantled and fitted with a new pipe system. This leads to large financial losses and also to the emergence of other technical operations due to revision.

As high requirements are placed on bimetal pipe bends, especially on their physical properties, the production of such parts is very complicated. There are many problems associated with this, such as the occurrence of possible defects and cracks in the manufacture of such a bend. Deformation occurs during the bending and it is necessary to monitor the minimum thickness of the outer wall, the deviation of the roundness, the corrugation on the inner side and the finding of surface defects [5].

In order to increase the service life and efficiency of the serpentine system from an economic point of view, it seems appropriate to use the existing $16 \mathrm{Mo} 3$ steel pipes with a cladding layer of Inconel 625 ensuring a longer service life of the part. By choosing this type of cladded material, higher heat resistance is achieved (in incinerators, the usual temperatures are $700^{\circ} \mathrm{C}$ up to $1100^{\circ} \mathrm{C}$ [6]) in a chemically aggressive environment containing chlorine and hydrogen. The novelty of the presented solution lies in the ability to create critical and supercritical bends of bimetal pipes (i.e. bends smaller than 1D, 
specifically $0.7 \mathrm{D}$ ) with Inconel 625 cladding, and this solution has not been published in any other study so far. Many critical areas and possible defects are generated by the forming bend of the pipe itself, so the study of the mechanism of the causes of these defects is a key aspect of the whole production. The obtained results are potentially very valuable not only from a theoretical point of view but especially from a practical point of view, when they will be used in optimizing the production of heat exchangers in the energy industry and for other shaped shapes.

\subsection{Literature review}

Fan [7] investigated the bi-metal pipes while the magnetic pulse cladding, namely they focused on the plastic deformation behaviour of the bi-metal pipes. The results revealed that the plastic deformation behaviour, which is not harmonious, caused the occurrence of a bamboo-like shape on the clad's outer surface. In addition to that, the magnetic pulse cladding helped to detect other two kinds of typical plastic deformation responses. Haghighat [8] also studied the bi-metal pipes as a material for their investigation while focusing on the analysis and finite element method (FEM) simulation of the extrusion process in an analytical and numerical ways. During the experiments the twisting length of the material and the extrusion pressure were defined, and the internal power the power dissipated on the surface were evaluated. Fan [9] used the magnetic pulse cladding process to study the fabrication of Al/Fe bi-metal pipes with outer tubular strong material component and the inner tubular layer of the corrosion-resistant material. During the experiment the bonding strength of the Al/Fe bi-metal pipes was described, on the basis of which the significant process parameters were determined, including the radial gap, discharging voltage, and feeding length. Jin [10] analysed the forming characteristic of the $\mathrm{Cu} / \mathrm{al}$ bi-metal pipes, i.e. a clad pipe and a base pipe, that emerged during the spinning process using a variety of simulations and experiments. The yield strength was considered to a great extent during the experiment. The influence of the feed rate and the press amount increasing was analysed in this process as well for the design bimetal composite pipe. Yu [11] studied the magnetic pulse cladding of aluminium alloy on mild steel pipe, the effect of the geometry of the field shaper and its impact on the quality of the cladding, and the main process parameters, like radial gap, feeding size and discharge voltage. The mechanical property was also estimated by setting precise process parameters. The results of the experiments revealed that the magnetic pulse cladding can form sound cladding bonds and can be used for a tubular clad component. Chen [12] investigated the bi-metal composite pipes and their butt weld with the focus on the failure analysis of the failed pipes with high pressure and temperature. For the analysis the following methods were employed: energy spectroscopy, scanning electron microscope, and metallographic examination. The results of the experiments showed that an amount of factors, like the organization of the weld, residual stress, special structure and corrosive media, lead to the corrosion of the metal and subsequently to the weld failure of the pipes. Fan [13] performed theoretical and numerical investigations of the production of the bi-metal corrosion-resistant alloy (CRA) -lined pipes in order to estimate the pressure of the hot water liquid, the hydraulic pressure and the contact force under different working conditions. The theoretical results correlated with the experimental results only when the temperature was low, in the case when the temperature was increased the results deviated. Tajyar [14] studied the mechanical properties of bi-metal squares pipes manufactured in the shape rolling process of $\mathrm{Al} / \mathrm{Cu}$ circular pipes, that were 
produced by the explosive welding process, which was then reshaped into the square pipe using the shape rolling process. Different stages of the shape rolling process were investigated and the mechanical properties of the pipes were evaluated. The following parameters were considered while the process: micro hardness along the thickness, shear testing and measurement of yielding. Dong [15] studied the bimetal pipe formation process using the experiments and simulations for the investigation. Threedimensional finite element method was employed for the stimulation of the pre-bending and J-shape, Cshape and 0-shape formation process of the bi-metal pipe, and the factors that affect the stresses were analysed. Later, the results obtained were compared with the outputs from the two-dimensional model. Dezhi [16] performed the theoretical and experimental study of the bi-metal pipes and their hydroforming. The deformation rule of the corrosion alloy liner and the outer pipe of carbon steel were analysed to get the deformation compatibility in the forming process. Also, a mechanical model was developed that helped to compute the hydroforming pressure of the bi-metal pipe. The experimental data obtained coincided with the results of the proposed model.

\subsection{Defining of critical points and specification of possible bending defects}

The bending process is technologically very demanding during which the pipe is deformed and the curvature of the part also changes. Several critical places need to be defined on the bent part. The first such place is the outer side of the pipe bend, where the wall is thinned due to stretching. On the inside part, on the other hand, the material is compacted due to compression, and at this place the wall corrugates. Another critical area is the suspension of the extended ends after bending, this process being caused by elastic deformations. During bending, the ovality (flattening) of the pipe is further formed, which is shown in FIG. 1 [20.22].

Before defining critical points, it is important to find out the technological criteria, such as the relative bending radius, the relative strength of the walls (thick-walled, thin-walled) and the degree of difficulty of the bending process. The determination of the bending radius is influenced by plasticity, wall thickness or the forming method. On the inside part, the thickness increases due to compression, and on the outside part, the wall thins due to stretching. After exceeding the tensile stress, which is equal to the tensile strength, the plasticity of the material is depleted and cracks are formed. For this reason, it is necessary to define the minimum wall thickness, which is determined by relation (1).

\section{See formula 1 in the supplementary files.}

where $t_{\min }(\mathrm{mm})$ is the required minimum pipe thickness, $t_{0}(\mathrm{~mm})$ is the initial wall thickness, $R_{0}(\mathrm{~mm})$ is the bend radius measured to the pipe axis and $D_{0}(\mathrm{~mm})$ is the nominal outside diameter of the pipe.

The second critical point is the corrugation on the inside part of the pipe bend. This is a multiple wave that occurs due to compacted material of the pipe and the subsequent loss of stability. This process can be suppressed or eliminated by the use of fillers and stabilizing inserts. It is also possible to use another method of bending technology. Another important place is the ovality (flattening) in the cross section. The internal dimensions of the pipe are checked only by a ball. For external dimensions, the check of a 
roundness $u$ is performed according to formula (2). For 1D bending, the limit value according to EN $12952-5$ [21] is $12 \%$ for one cold bending operation. For a $0.7 D$ bend, there is no limit value for one operation. [22,23]

\section{See formula 2 in the supplementary files.}

where $u(\%)$ is the deviation of the roundness, $D_{\max }(\mathrm{mm})$ is the maximum outer diameter measured at the top of the tubular profile and $D_{\min }(\mathrm{mm})$ is the minimum outer diameter measured at the same place as $D_{\max }$

The suspension of the pipe bend is an event caused by elastic deformations during bending, which disappear after the release of the load. The shape of the bent part will not copy the exact shape of the tool after bending. Plastic deformation determines the final shape of the pipe end. The final value of the bending radius after release is determined by means of the residual radius $R_{s b}$, which is given by equation (3). After releasing the bending moment, the bent part retains these values [24,25].

\section{See formula 3 in the supplementary files.}

where $R_{s b}(\mathrm{~mm})$ is the residual radius, $M_{O}(\mathrm{~N} \cdot \mathrm{mm})$ is the bending moment, $E(\mathrm{MPa})$ is the modulus of elasticity of the material in tension, $\mathrm{J}\left(\mathrm{mm}^{4}\right)$ is the quadratic moment of the cross section.

\section{Experimental Setup And Material}

The subject of the research is a bimetal material in the form of a pipe, the inner base material of which is $16 \mathrm{Mo} 3$ steel, on which a 2 up to $4 \mathrm{~mm}$ thick layer of Inconel 625 material was cladded, which is shown in Figs. 2 (a) including its microstructure obtained using the light microscopy (LM). The area closest to the Inconel layer is the melting area where martensite needles have been formed. Below is the superheat transition area, where there was no transformation but only coarsening of the ferrite grains, while at the grain boundaries there is perlite with small precipitated carbide particles. The furthest area from Inconel is the area of ferrite and perlite, which characterizes the base material. Cold Metal Transfer (CMT) welding technology was used for cladding of the Inconel 625 material, which ensures a lower value of heat introduced into the weld and only about $0.2 \mathrm{~kJ} \cdot \mathrm{mm}^{-1}$. The dimensions of the steel pipe before cladding and the bending itself were: outer diameter - $38 \mathrm{~mm}$, inner diameter - $26 \mathrm{~mm}$. The bending process was performed on a $\mathrm{CH} 120$ type bending machine from Amob. The bending of the pipes into the required shapes occurs only after the cladding itself, while cold forming without a mandrel was used. These pipes form a serpentine system, with critical bends of 1D (see Fig. 2 (b)) and supercritical bends $0.7 D$ (see Fig. 2 (c)).

In the performed experiment, a total of 6 pieces of bends 0.7D were produced, which are shown in Figs. 2 (d), each pipe being made according to the parameters given in Tab. 1, where the result of the performed capillary test according to the standard EN ISO 3452-1 [19] (due to the occurrence of cracks) is also described, the procedure of which was as follows. The first step of the test was to clean the test surface 
of the pipe bend with a solvent to remove impurities. Next, a penetration layer was evenly applied to the part, and after the penetration time, the excess penetrant was removed. In the final phase, a white-powderlike developer was applied to the test surface of the pipebend with a uniform thin layer to provide a background contrast. Unfortunately, there were cracks on a total of 4 samples out of 6 . The machine setting parameters were selected on the basis of extensive previous tests and based on the recommendations of the bending machine manufacturer.

Tab. 1 Parameters for bending of individual pipes, including the occurrence of cracks

\begin{tabular}{|llll|}
\hline Sample number & Compression force $(\mathrm{MPa})$ & Bending speed $\left({ }^{\circ} \cdot \mathrm{s}^{-1}\right)$ & Occurrence of cracks \\
\hline 1 & 8 & 2 & No \\
\hline 2 & 8 & 2 & Yes \\
\hline 3 & 8 & 2 & Yes \\
\hline 4 & 8 & 2 & Yes \\
\hline 5 & 16 & 1 & Yes \\
6 & 16 & 1 & No \\
\hline
\end{tabular}

\section{Results And Discussion}

\subsection{Experimental methods}

In order to be able to perform the analysis of the cladding layer, to display the microstructure and also to perform the hardness measurement, it was necessary to create a metallographic preparation from Pipe 1 , which will contain both the cladded Inconel part and the basic steel pipe. The pipe was cut using a metallographic saw of the Viper 300M2 type from LECO. Furthermore, the sample was hot pressed into the Struers ISO fast molding compound on a PR4X type metallographic press from LECO. After pressing, the surface was mechanically grinded on a semi-automatic grinder/polisher PX500 type from LECO. Furthermore, the sample was prepared using conventional techniques, followed by polishing with Premium Grade diamond paste from LECO. The produced metallographic preparation was further examined using a Neophot 32 light microscope from ZEISS. A fully automatic hardness tester of AMH55 type from LECO was used to measure Vickers hardness. A 3D scanner of the Atos Compact scan 2M, MV 250 type from GOM was used for the analysis of roundness deviations. Tensile test specimens were made on a Robocut Alpha-0iD type WEDM electric discharge cutter (WEDM) using a $0.25 \mathrm{~mm}$ radius of Cut-G coated wire electrode from Penta Trading. The tensile test was performed on a universal blasting machine of the Zwick Z 100 type from the ZwickRoell Group. The fracture surface of the test specimens was analysed using electron microscopy on a Vega 5135 scanning electron microscope (REM) from TESCAN.

3.2 Pipe bending - shape and dimensional analysis 
Due to the complexity of the bending process, it is necessary to achieve the required parameters, which are: minimum wall thickness, permissible deviation of roundness, corrugation or surface, which must be free of defects (scratches, nicks or cracks). Many critical areas and possible defects are generated by the forming bend of the pipe itself, while the elimination of cracking will enable greater production of individual products. In the supercritical bend of 0.7D shown in Fig. 2 (c), the ratio of the shortening of the wall on the inner side to the extension on the outer side is $1: 6$, and thus the force load is significantly changed and at the same time the space of the system is reduced. In this bend, the susceptibility to the formation of defects and possible cracks is much greater than within the 1D bend shown in Fig. 2 (b) because more force is required for bending.

The measurement of the wall thickness of the pipe bend was carried out on a pre-prepared metallographic preparation obtained after cutting the pipe bend from Sample 1 (pipe bend with a bend of 0.7 completely without cracks) in the longitudinal direction, while the separate measurement places using the light microscopy Zeiss Neophot are depicted in Fig. 3. The thickness measurement was performed at approximately $60^{\circ}$ in three places. The thickness values are approximately the same at all measuring places. The average wall thickness of the Inconel 625 cladded part measured in the middle part is 2.64 $\mathrm{mm}$ (standard deviation is $0.05 \mathrm{~mm}$ ), in the left $-2.55 \mathrm{~mm}$ (standard deviation is $0.02 \mathrm{~mm}$ ) and in the right part $2.64 \mathrm{~mm}$ (standard deviation is $0.03 \mathrm{~mm}$ ). The average thickness of the cladding layer is therefore $2.61 \mathrm{~mm}$. These dimensions confirm the good quality of the cladding layer (limit values of the cladding layer are 2 up to $4 \mathrm{~mm}$ ) and enable the correct functioning of the pipe bend. The analysis of the uniform wall thickness of the welded layer is not only important for pipes used in waste incinerators, as in this case but also for pipes used for fuel, which will withstand a possible accident and prevent collapse of the pipe wall, which was studied in Kim study [17]. Furthermore, the wall thickness of the pipe was also analysed in the case of the explosive cladding method presented in the Mróz study [18].

The measurement of roundness deviations and deviations from the computer-aided design (CAD) model was performed using an Atos Compact 3D scanner. Pipebend 1 was subjected to this analysis, and before the measurement it was necessary to degrease the sample, stick the points needed to determine the position and apply an anti-reflective spray for better visibility. For the pipe bend, 7 cuts were made, which are shown in Fig. 4 (a), analysing the roundness deviations for both the outer and inner pipe dimensions. The cuts are placed $45^{\circ}$ from the second to the sixth cut, and the cuts are parallel at the extended ends. The individual values of the deviation of the roundness of external and internal dimensions were calculated according to relation (2) and subsequently processed into Tab. 2 . The limit value for external roundness for cold-bent bends 0.7D is not specified in EN 12952-5 [21] or otherwise. Likewise, the standard does not affect the forming of bimetal materials. For this reason, the data from the mentioned standard is used, which for similar applications (bend 1.5D) states a deviation of outer roundness of up to $18 \%$. This value is taken as the maximum deviation for this application as well. From the calculated roundness deviations for the external dimensions shown in Tab. 2, it is clear that none of the values exceeded the set assumption of $18 \%$. For the internal dimension, the deviation of the roundness is not specified by the standard and its control is subject only to the ball test passing through the pipe bend, which was successful for the given sample. The analysis of the internal shape and the 
evaluation of the deviations of the roundness of the cavity was performed only to verify the achieved values after the deformation in the bend and the calculated values of the deviations of the roundness for the internal dimensions, see Tab. 2, were used only for control verification. The course of deviations against the CAD model and the individual measured diameters in Cut 4 are shown in Fig. 4 (b, c). From these deviations, it is clear that in some places, due to the bending process, more significant deformations occurred, but these deformations do not affect the proper functioning of the pipe bend. A similar comparison of the differences of the CAD model from the actual pipe was also performed in the $\mathrm{Li}$ study [23].

Tab. 2 Deviations of the roundness of the outer and inner dimensions of the pipe bend

\begin{tabular}{|llll|}
\hline \multicolumn{4}{|l}{ External dimensions } \\
\hline Cut number & $\mathrm{D}_{\max }(\mathrm{mm})$ & $\mathrm{D}_{\min }(\mathrm{mm})$ & $\mathrm{u}(\%)$ \\
\hline 1 & 43.78 & 43.03 & 1.72 \\
\hline 2 & 42.71 & 41.75 & 2.27 \\
\hline 3 & 42.26 & 37.32 & 12.41 \\
\hline 4 & 42.54 & 39.55 & 7.28 \\
\hline 5 & 42.72 & 39.49 & 7.85 \\
\hline 6 & 43.57 & 41.23 & 5.51 \\
\hline 7 & 44.66 & 43.45 & 2.74 \\
\hline Internal dimensions & & \\
\hline Cut number & $\mathrm{D}_{\max }(\mathrm{mm})$ & $\mathrm{D}_{\min }(\mathrm{mm})$ & $\mathrm{u}(\%)$ \\
\hline 1 & 25.34 & 24.56 & 3.12 \\
\hline 2 & 24.19 & 22.08 & 9.12 \\
\hline 3 & 23.19 & 16.91 & 31.32 \\
\hline 4 & 22.82 & 17.76 & 24.93 \\
\hline 5 & 23.31 & 18.45 & 23.27 \\
\hline 6 & 24.51 & 19.91 & 20.71 \\
\hline 7 & 25.37 & 22.58 & 11.63 \\
\hline
\end{tabular}

- The hardness analysis of the pipe according toVickers at low load

The hardness analysis was performed on a previously prepared metallographic preparation (prepared from Sample 1) shown in Fig. 3, where the automatic hardness tester AMH 55 was used for the 
measurement. The measurement was performed according to the valid standard EN ISO 6507-1 [26], a load of $0.3 \mathrm{kgf}$ was used and the distances between the individual impressions were $150 \mu \mathrm{m}$. The distances of the impressions from the edge of the sample were $120 \mu \mathrm{m}$ and the time delay under load was $10 \mathrm{~s}$. A total of 6148 indents were created, which were assembled into the map shown in Fig. 5 (a) from which the different hardness of the individual materials is clearly visible due to the colour scale. The highest hardness, locally up to $329 \mathrm{HV}_{0.3}$, is reached by Inconel 625 , which is in line with the Feng study [27], although other cladding technologies have been used as a comparison. Conversely, when using a laser cladding of Inconel 625, whether in the form of wire or powder, a hardness of a maximum of 245 $\mathrm{HV}_{0.3}$ was achieved in the Abioye study [28] for powder welding and $224 \mathrm{HV}_{0.3}$ in the form of wire. Another material examined was a base pipe made of $16 \mathrm{Mo} 3$ steel, which had an average hardness according to the graph shown in Fig. 5 (b) $172 \mathrm{HV}_{0.3}$, with the maximum value being $202 \mathrm{HV}_{0.3}$. The heat affected zone (HAZ), thezone between the two metals (considered in the total width of $1 \mathrm{~mm}$ ) had a hardness from 192 to $240 \mathrm{HV}_{0.3}$, which is completely in line with the Soleck study [29].

- Tensile tests and the analysis of fracture surfaces

The test consists in deforming the test specimen by a tensile load into the fracture, in order to determine the mechanical properties of the material of which the test specimen was made. For the tensile test, a total of six test specimens (shown in Fig. 6 (c)) were produced according to the ISO 6892-1 standard [30], which were taken from individual zones of Pipe 1 according to Fig. 6 (a). It was one specimen from the cladding zone of Inconel 625 , then three specimens from the heat-affected zone between the materials and one specimenfrom the zone of the base material of the $16 \mathrm{Mo} 3$ pipe. Another test specimen contained all the mentioned zones of the pipe (Inconel cladding, HAZ and the base pipeof 16Mo3) and was hereinafter referred to as Pipe. These bodies were manufactured using a Robocut Alpha-0iD wire EDM machine, all of which were $1.5 \mathrm{~mm}$ thick and only the last body containing all areas was $6.1 \mathrm{~mm}$ thick.

From the obtained tensile test results shown in Fig. 6 (b) and in Tab. 3, it can be seen that the values of the yield strength are $460 \mathrm{MPa}$ and the values of the tensile strength are $594 \mathrm{MPa}$ of the tested sample from the zone of the base material of the $16 \mathrm{Mo3}$ pipe reach higher values than in the material sheet [31]. In contrast, the determined value of tensibility is approximately one third compared to the value stated in the material sheet. The difference between the values obtained by the tensile test and the values given by the material sheet can be caused, for example, by different heat treatment of the material before the tensile test. The material sheet of steel $16 \mathrm{Mo} 3$ states that all the mechanical properties stated in it are given for the material which is in the state after normalization annealing. Since a cladding was applied to the original normalized annealed pipe and a sample was taken near the melting limit (due to the shape of the pipe), the material can no longer be considered as normalized annealed. In the case of the sample from the cladding metal zone of Inconel 625, the values found (yield strength of $465 \mathrm{MPa}$ and tensile strength of $723 \mathrm{MPa}$ ) were not compared with the values given in the material sheet, as this comparison would not be meaningful (the comparison of cladding material and wire material, bar or flat product in the basic annealed state is not possible). Data from the Yang study [32], who addressed a similar issue, 
were used for comparison. When comparing the values obtained by the tensile test with the values reported in the Yang study, it can be said that the values of the tensile strength and the yield strength are almost identical. The only difference is in the comparison of tensibility values. This difference could be caused, for example, by a different choice of the basic length of the test specimen. The value of tensibility and tensile strength in the heat affected zone is the lowest of all examined zones, which was caused by cladding. Welding theory states that mechanical properties deteriorate in the immediate closeness of the weld (heat affected zone). Both the value of tensibility and the tensile strength of the material decrease, while the value of hardness and the force required to create plastic deformation increases. This theory is also supported by the hardness map shown in Fig. 5 (a). From the results of the mechanical properties of the test specimen containing all zones (Inconel cladding, HAZ and 16Mo3 base pipe) it is clear that the values from the entire wall thickness of the pipe do not reach such values as other homogeneous zones (16Mo3 steel, Inconel 625). The decrease in values could be caused, for example, by different crack propagation during the test for a specimen containing the entire wall thickness of the pipe or also because the homogeneous specimenscollected contained only parts of the given zones exhibit other mechanical properties.

Tab. 3 Mechanical properties obtained from tensile tests

\begin{tabular}{|lllllll|}
\hline \multicolumn{7}{|c|}{ Test specimen material } \\
Parameter & Inconel & HAZ1 & HAZ2 & HAZ3 & $16 M o 3$ & Pipe \\
\hline Tensile strength $\mathrm{R}_{\mathrm{m}}(\mathrm{MPa})$ & 723.78 & 517.11 & 523.93 & 629.37 & 594.56 & 573.70 \\
\hline Yield strength $\mathrm{Rp}_{0.2} / \mathrm{R}_{\mathrm{e}}(\mathrm{MPa})$ & 465.45 & 464.20 & 424.50 & 528.00 & 460.22 & 425.02 \\
\hline Maximum acting force $\mathrm{F}_{\mathrm{m}}(\mathrm{kN})$ & 7.19 & 5.73 & 5.21 & 4.75 & 5.91 & 28.00 \\
\hline Tensibility A (\%) & 26.13 & 5.53 & 4.29 & 5.73 & 10.60 & 35.00 \\
\hline Contraction Z (\%) & 39.92 & 40.47 & 44.21 & 34.25 & 30.20 & 23.53 \\
\hline
\end{tabular}

The analysis of the fracture surfaces was performed using a Vega 5135 scanning electron microscope on a total of three fracture surfaces of the test specimens. It is a specimenof Inconel, HAZ3 and 16Mo3.

REM images of individual fracture surfaces, including their details, are shown in Fig. 7. From the image of the fracture surface of the Inconel test specimen shown in Fig. 7 (a), it is clear that this is a transcrystalline ductile failure of the material. When comparing ductile and fissile failure, it can be said that ductile failure requires significantly more energy than fissile failure. Nucleation (formation), growth and then coalescence (connection) of microcavities (disorders) occurred in the areas of failure. The formation of microcavities usually occurs on particles of the secondary phase, which are located in the basic matrix and they can be, for example, inclusions, carbides or precipitates. These particles tend to be less tough in most cases than the base matrix. Therefore, if there is a more significant flow of material (e.g. during the tensile test), microcavities begin to form and gradually their growth begins. These bridges 
gradually narrow, their constriction occurs and in the end they reach $100 \%$ contraction (shrinkage). The individual cavities formed interconnect and together form the final transcrystalline ductile fracture, which can be observed macroscopically. The size of the gaps between the constricted bridges ranges from $2 \mu \mathrm{m}$ to $8 \mu \mathrm{m}$, which can be seen from the detail in Fig. 7 (a). As in the previous case, there is a ductile transcrystalline fracture in the fracture surface of the HAZ3 specimen, which is evident from Fig. 7 (b). The mechanism of the fracture formation was identical, however, a significant difference lies in the magnitude of deformation of the fracture of the bridges between the individual cavities. This fracture is much more significantly deformed in the direction of the stress (which was dominant during the tensile test) than in the case of the fracture of the Inconel test specimen. The last fracture surface evaluated was that of a test specimen made of $16 \mathrm{Mo} 3$ steel, and is shown in Fig. 7 (c). Here, a significant chipping of the surface layer of the material is evident, however, it is again a ductile fracture. There is also a noticeable change in the structure of the ductile fracture, when there is a gradual refinement of the structure from the farther to the nearest edge of the fracture. Such a change in structure was apparently caused by crack propagation in the test specimen. The crack probably spread from the far edge to the nearer. As soon as a significant part of the sample material was disruption due to crack propagation, the remaining material was immediately separated, resulting in a fine fracture structure as well as a partial peeling of the surface layer of the sample material. Similar fracture surfaces of a bimetalpipe were also studied in the publication by Faida [33] or Tajyar [34].

\section{Conclusions}

In order to comprehensively investigate bimetal pipe bends with a bend of 0.7D with a cladding layer of Inconel 625, many analyses were performed, examining both the bend itself and the summary of mechanical properties of the bimetal pipe. Based on these analyses, the following conclusions were reached:

- a pipe bend made of bimetal pipe with a bend of $0.7 \mathrm{D}$ without defects and cracks was successfully manufactured,

- the thicknesses of the claddinglayer of Inconel 625 are approximately the same at all places in the pipe, the average thickness of the claddinglayer being $2.61 \mathrm{~mm}$, which confirms the good cladding quality (limit values of the cladding layer are 2 to $4 \mathrm{~mm}$ ) and allows the pipe bend to function properly,

- the analysis of the roundness deviations revealed that for the external dimensions none of the measured values exceeded the standard deviation, whereas for the internal dimension the roundness deviation is not specified by the standard and its control was successful by a ball test,

- the highest hardness, locally up to $329 \mathrm{HV}_{3}$, is reached by the material Inconel 625 , the base pipe made of $16 \mathrm{Mo} 3$ steel had a hardness from $172 \mathrm{HV}_{0.3}$ to $202 \mathrm{HV}_{0.3}$ and the heat affected zone between the two metals had a hardness from 192 to $240 \mathrm{HV}_{0.3}$,

- the results of tensile tests show that the determined values of yield strength of $460 \mathrm{MPa}$ and tensile strength of $594 \mathrm{MPa}$ from the base material of the pipe $16 \mathrm{Mo} 3$ reach higher values than in the 
material sheet, but in the case of Inconel 625 cladding the determined values were not possible (yield strength of $465 \mathrm{MPa}$ and tensile strength of $723 \mathrm{MPa}$ ) to compare,

- for all examined test specimens made of parts of a bimetalpipe (Inconel 625, heat-affected zone, $16 \mathrm{Mo} 3$ steel), a transcrystalline ductile failure of the material occurred during the tensile test.

From the above-mentioned conclusions, it can be clearly stated that there was a successful production of a pipe bend from a bimetal pipe with a bend of $0.7 \mathrm{D}$ without defects, while the mechanical properties of the bimetal pipe fully meet the high demands placed on them in the industry.

\section{Declarations}

The work presented in this paper has been supported by the specific research project 2020 "SV20-216" at the Department of Mechanical Engineering, University of Defence in Brno and the Project for the Development of the Organization "DZRO VARoPs".

Declarations

Competing Interests

The authors declare that they have no competing interests.

Consent to publish

Consent is given to publish.

Ethical approval

The manuscript contains original ideas which have never been published before in other journals.

Consent to participate

Consent is given to participate.

Funding

This research was supported by Project No. FV40173 within the fourth public tender in the TRIO program of the Ministry of Industry and Trade.

Availability of data and materials

Not applicable

\section{References}


[1]Y. Wang, J. Yuan, Y. Zhang,C. Guo, Technology status and development direction of bimetal pipe. Welded Pipe and Pipe, 36(2)(2013) 05-09.

[2]A. M. Torbati, R. M. Miranda, L. Quintino,S. Williams, Welding bimetal pipes in duplex stainless steel. The International Journal of Advanced Manufacturing Technology, 53(9-12)(2011) 1039-1047.

[3]A. Søe-Knudsen, Design of stop-band filter by use of curved pipe segments and shape optimization. Structural and Multidisciplinary Optimization, 44(6) (2011) 863-874.Y.Wang,

[4]Flat products made of steels for pressure purposes - Part 2: Non-alloy and alloy steels with specified higher temperature properties. EN 10028-2 (420937). (2018).

[5]P. Rizzo, I. Bartoli, A. Marzani,F. Lanza di Scalea, Defect classification in pipes by neural networks using multiple guided ultrasonic wave features extracted after wavelet processing 127(3) (2005) 294-303.

[6]W. H. Chen, Waste burning and heat recovery characteristics of a mass burn incineration system. Journal of the Air \& Waste Management Association, 53(2) (2003) 136-142.

[7] Z. Fan, H. Yu, C. Li, Plastic deformation behavior of bi-metal pipes during magnetic pulse cladding: FE analysis and experiments. Journal of Materials Processing Technology, 229 (2016) 230-243.

[8] H. Haghighat, M. M. Mahdavi, Analysis and FEM simulation of extrusion process of bimetal pipes through rotating conical dies. Transactions of Nonferrous Metals Society of China, 23(11) (2013) 33923399.

[9] Z. Fan, H. Yu, F. Meng, C. Li, Experimental investigation on fabrication of Al/Fe bi-metal pipes by the magnetic pulse cladding process. The International Journal of Advanced Manufacturing Technology, 83(5-8) (2016) 1409-1418.

[10] K. Jin, Q. Yuan, J. Tao, J. Domblesky, X. Guo, Analysis of the forming characteristics for Cu/Al bimetal pipes produced by the spinning process. The International Journal of Advanced Manufacturing Technology, 101(1-4) (2019) 147-155.

[11] H. Yu, Z. Fan,C. Li, Magnetic pulse cladding of aluminum alloy on mild steel pipe. Journal of Materials Processing Technology, 214(2)(2014) 141-150.

[12] H. Chen, H. Ma, X. Chen, S. Jiang, H. Wang, Failure analysis of butt weld of bimetal composite pipes. Journal of Failure Analysis and Prevention, 15(4) (2015) 563-570.

[13] X. Fan, X. Wang,Q. Chen, Theoretical and numerical investigations of manufacturing bimetal CRA-lined pipes using thermo-hydraulic forming. Journal of Thermal Analysis and Calorimetry, (2020).

[14] A. Tajyar, A. Masoumi, Investigation of mechanical properties of bimetallic square pipes produced by shape rolling of Al/Cu circular pipes. Journal of Mechanical Science and Technology, 30(9)(2016) 4299- 
4306.

[15] Z. Dong, Z. Xu, W. Wang, Z., Bi,J. Zhang, Numerical Simulation and Experimental Confirmation of a Bimetallic Pipe Forming Process. Materials, 13(16) (2020) 3561.

[16] Z. Dezhi, D. Kuanhai, S. Taihe, L. Yuanhua, Z. Hongjun, L. Tianlei,S. Yongxing, Theoretical and experimental study of bimetal-pipe hydroforming. Journal of pressure vessel technology, 136(6) (2014) 061402.

[17]H. K. Kim, H. G. Kim, J. H. Yang,Y. H. Koo, On the minimum thickness of FeCrAl cladding for accidenttolerant fuel. Nuclear Technology, 198(3)(2017) 342-346.

[18]S. Mróz, G. Stradomski, H. Dyja,A. Galka, Using the explosive cladding method for production of Mg-Al bimetallic bars. Archives of Civil and Mechanical Engineering, 15(2), (2015) 317-323.

[19]Non-destructive testing - Penetrant testing - Part 1: General principles. EN ISO 3452-1 (2015).

[20]S. S. Sorour, M. Shazly,M. M. Megahed, Limit load analysis of thick-walled as-fabricated pipe bends under in-plane moment loading and internal pressure. International Journal of Pressure Vessels and Piping, 174(2019) 1-12.

[21]Water-pipe boilers and auxiliary installations - Part 5: Workmanship and construction of pressure parts of the boiler. EN 12952-5 (2012).

[22]R. S. Kumar, B. N. Rao, K. Velusamy, G. Sasikala,S. Jalaldeen, Fatigue crack growth material parameters-based on prototype pipe bend test and comparison with conventional parameters. International Journal of Pressure Vessels and Piping, 188(2020) 104209.

[23]J. Li, C. Y. Zhou, J. G. Zhu, Limit loads for $180^{\circ}$ pipe bends under in-plane bending moment considering geometric nonlinearity. International Journal of Pressure Vessels and Piping, (2020) 104100.

[24]Z. Hu, Elasto-plastic solutions for spring-back angle of pipe bending using local induction heating. Journal of Materials Processing Technology, 102(1-3)(2000) 103-108.

[25]J. Zhao, J. Yin, R. Ma, L. Ma, Springback equation of small curvature plane bending. Science China Technological Sciences, 54(9)(2011) 2386-2396.

[26] Metallic materials - Vickers hardness test - Part 1: Test method. EN ISO 6507-1 (2018).

[27]K. Feng, Y. Chen, P. Deng, Y. Li, H. Zhao, F. Lu,...\&Z. Li, Improved high-temperature hardness and wear resistance of Inconel 625 coatings fabricated by laser cladding. Journal of Materials Processing Technology, 243 (2017) 82-91.

[28]T. E. Abioye, P. K. Farayibi, A. T. Clare, A comparative study of Inconel 625 laser cladding by wire and powder feedstock. Materials and Manufacturing Processes, 32(14)(2017) 1653-1659. 
[29]M. Solecka, A. Kopia, A. Radziszewska,B. Rutkowski, Microstructure, microsegregation and nanohardness of CMT clad layers of Ni-base alloy on $16 \mathrm{Mo} 3$ steel. Journal of Alloys and Compounds, 751(2018) 86-95.

[30]Metallic materials - Tensile testing - Part 1: Method of test at room temperature. ISO 6892-1 (2020).

[31]Material No.: 1.5415. M.WoiteSonderwerkstoffeEdelstähle [online]. Erkrath: M. Woite, 2012 [cit. 202010-27]. http://www.woite-edelstahl.com/15415en.html\#.

[32]Z. Yang, S. Kumar,J. P. Tronskar, ECA of Pipeline With Girth Weld Strength Mis-Matching Subjected to Large Strain. International Conference on Offshore Mechanics and Arctic Engineering, 43468(2009) 7582.

[33]C. Faidy, Structural Integrity of Bi-Metallic Welds in Piping Fracture Testing and Analysis. In ASME Pressure Vessels and Piping Conference, 48241(2008) 191-200.

[34]A. Tajyar,A. Masoumi, Experimental analysis of bonding strength in shape rolling of Al-Cu bimetallic circular pipes into square pipes. Proceedings of the Institution of Mechanical Engineers, Part C: Journal of Mechanical Engineering Science, 231(22)(2017) 4087-4098.

\section{Tables}

Tab. 1 Parameters for bending of individual pipes, including the occurrence of cracks

\begin{tabular}{|c|c|c|c|}
\hline Sample number & Compression force $(\mathrm{MPa})$ & Bending speed $\left({ }^{\circ} \cdot \mathrm{s}^{-1}\right)$ & Occurrence of cracks \\
\hline 1 & 8 & 2 & No \\
\hline 2 & 8 & 2 & Yes \\
\hline 3 & 8 & 2 & Yes \\
\hline 4 & 8 & 2 & Yes \\
\hline 5 & 16 & 1 & Yes \\
\hline 6 & 16 & 1 & No \\
\hline
\end{tabular}

Tab. 2 Deviations of the roundness of the outer and inner dimensions of the pipe bend 


\begin{tabular}{|c|c|c|c|}
\hline \multicolumn{4}{|c|}{ External dimensions } \\
\hline Cut number & $\mathrm{D}_{\max }(\mathrm{mm})$ & $\mathrm{D}_{\min }(\mathrm{mm})$ & $\mathrm{u}(\%)$ \\
\hline 1 & 43.78 & 43.03 & 1.72 \\
\hline 2 & 42.71 & 41.75 & 2.27 \\
\hline 3 & 42.26 & 37.32 & 12.41 \\
\hline 4 & 42.54 & 39.55 & 7.28 \\
\hline 5 & 42.72 & 39.49 & 7.85 \\
\hline 6 & 43.57 & 41.23 & 5.51 \\
\hline 7 & 44.66 & 43.45 & 2.74 \\
\hline \multicolumn{4}{|c|}{ Internal dimensions } \\
\hline Cut number & $\mathrm{D}_{\max }(\mathrm{mm})$ & $\mathrm{D}_{\min }(\mathrm{mm})$ & $\mathrm{u}(\%)$ \\
\hline 1 & 25.34 & 24.56 & 3.12 \\
\hline 2 & 24.19 & 22.08 & 9.12 \\
\hline 3 & 23.19 & 16.91 & 31.32 \\
\hline 4 & 22.82 & 17.76 & 24.93 \\
\hline 5 & 23.31 & 18.45 & 23.27 \\
\hline 6 & 24.51 & 19.91 & 20.71 \\
\hline 7 & 25.37 & 22.58 & 11.63 \\
\hline
\end{tabular}

Tab. 3 Mechanical properties obtained from tensile tests

\begin{tabular}{|l|c|c|c|c|c|c|}
\hline & \multicolumn{7}{|c|}{ Test specimen material } \\
\hline Parameter & Inconel & HAZ1 & HAZ2 & HAZ3 & 16 Mo3 & Pipe \\
\hline Tensile strength $\mathrm{R}_{\mathrm{m}}(\mathrm{MPa})$ & 723.78 & 517.11 & 523.93 & 629.37 & 594.56 & 573.70 \\
\hline Yield strength $\mathrm{Rp}_{0.2} / \mathrm{R}_{\mathrm{e}}(\mathrm{MPa})$ & 465.45 & 464.20 & 424.50 & 528.00 & 460.22 & 425.02 \\
\hline Maximum acting force $\mathrm{F}_{\mathrm{m}}(\mathrm{kN})$ & 7.19 & 5.73 & 5.21 & 4.75 & 5.91 & 28.00 \\
\hline Tensibility A (\%) & 26.13 & 5.53 & 4.29 & 5.73 & 10.60 & 35.00 \\
\hline Contraction Z $(\%)$ & 39.92 & 40.47 & 44.21 & 34.25 & 30.20 & 23.53 \\
\hline
\end{tabular}

\section{Figures}



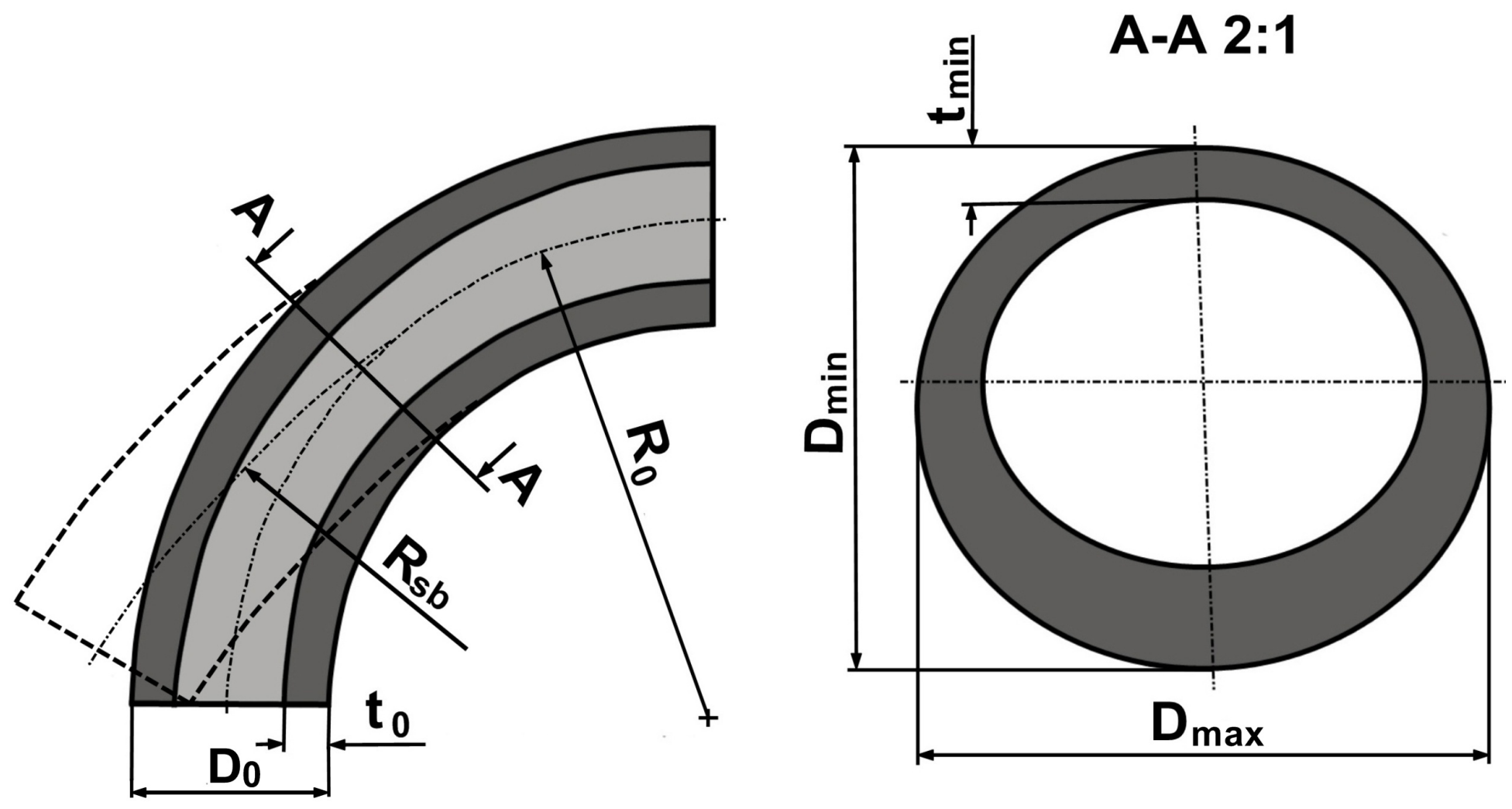

Figure 1

Cross-section of the pipe bend including its suspension and cross-sectional view A-A. 
(a)
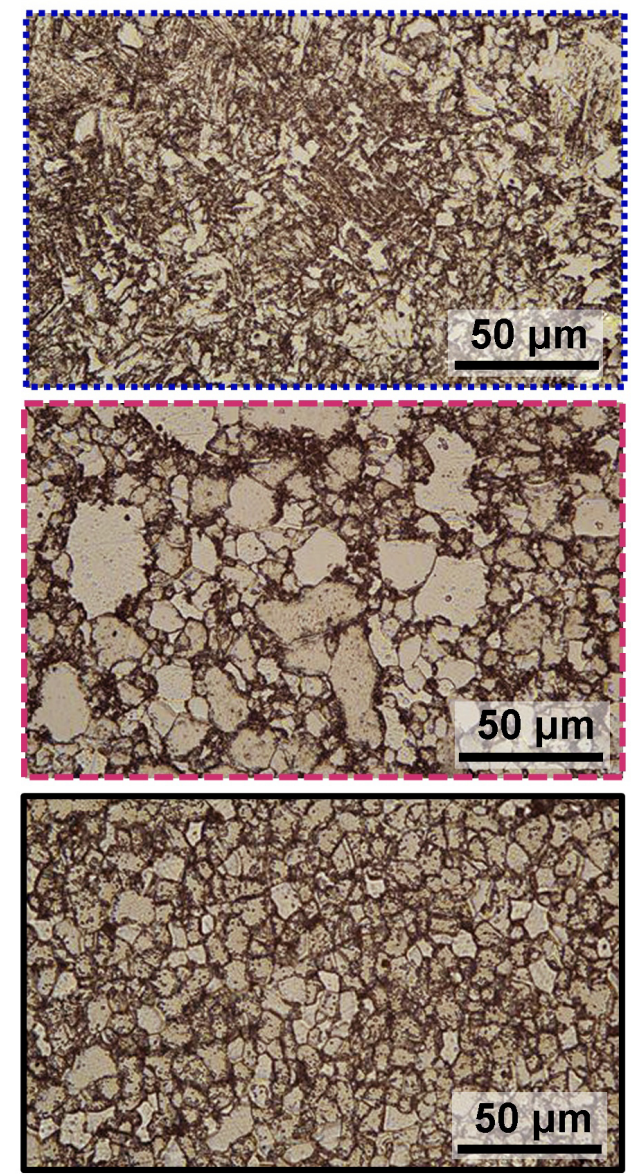

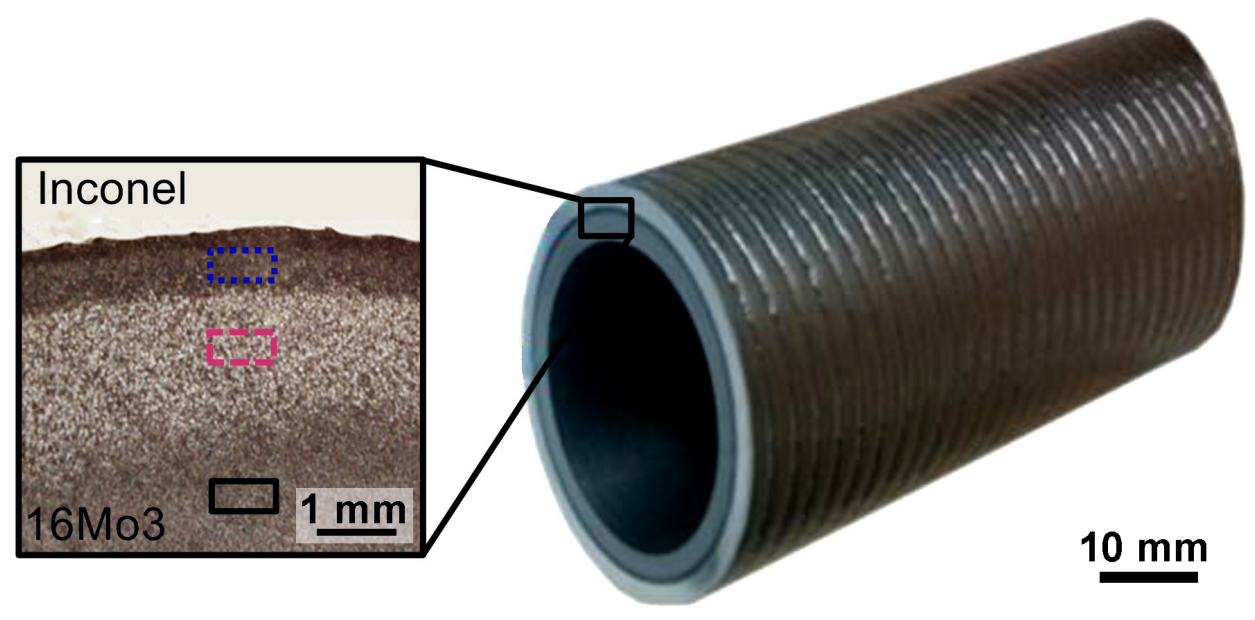

(b)

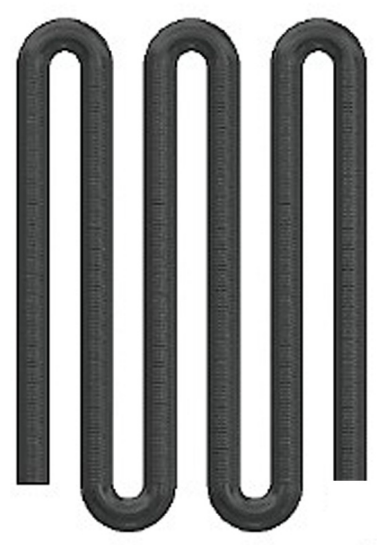

(c)

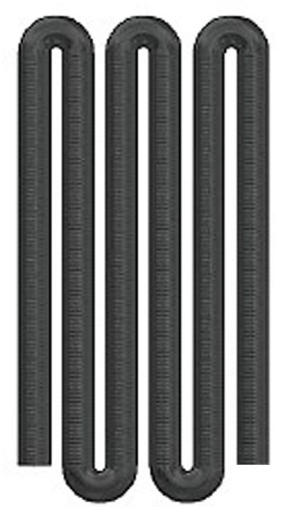

(d)

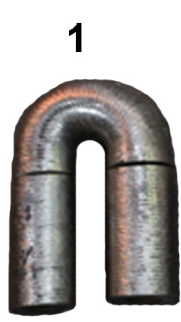

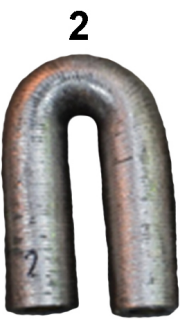
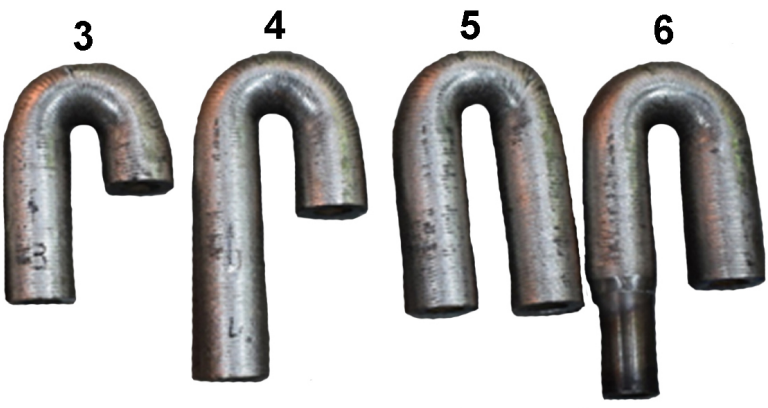

Figure 2

Bimetalpipe including the representation of microstructures in individual places (LM), (b) the serpentine system with critical bending 1D, (c) the serpentine system with supercritical bending 0.7D, (d) individual samples of the performed experiment. 


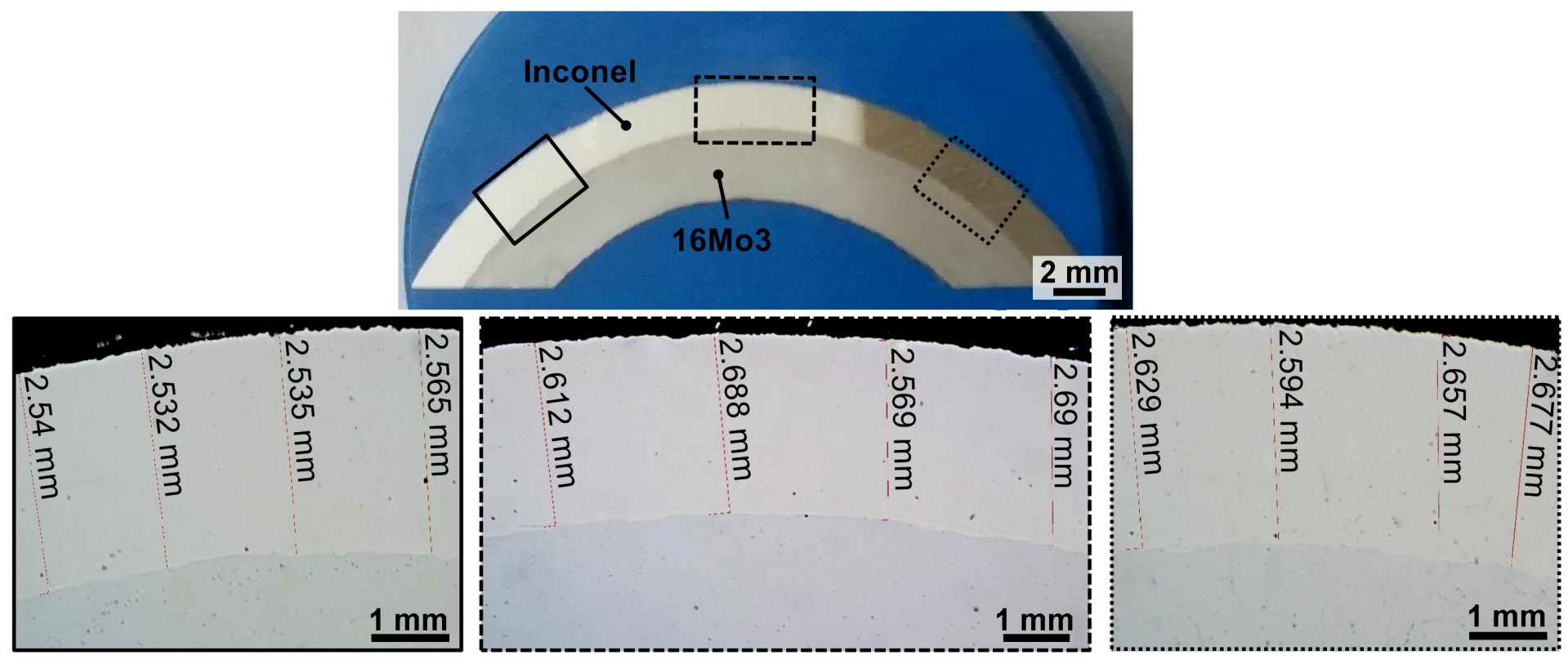

Figure 3

Metallographic cut with part of the pipe and places for individual measurements of thickness of Inconel 625 cladding. 

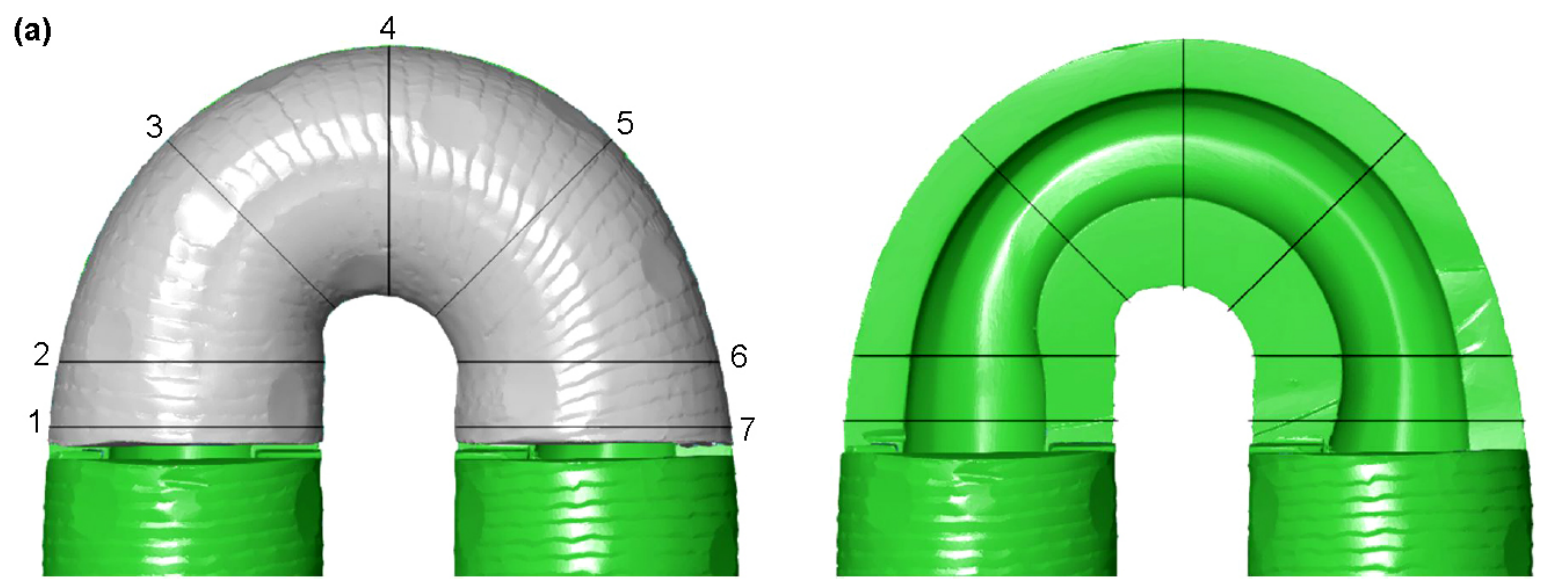

(b)
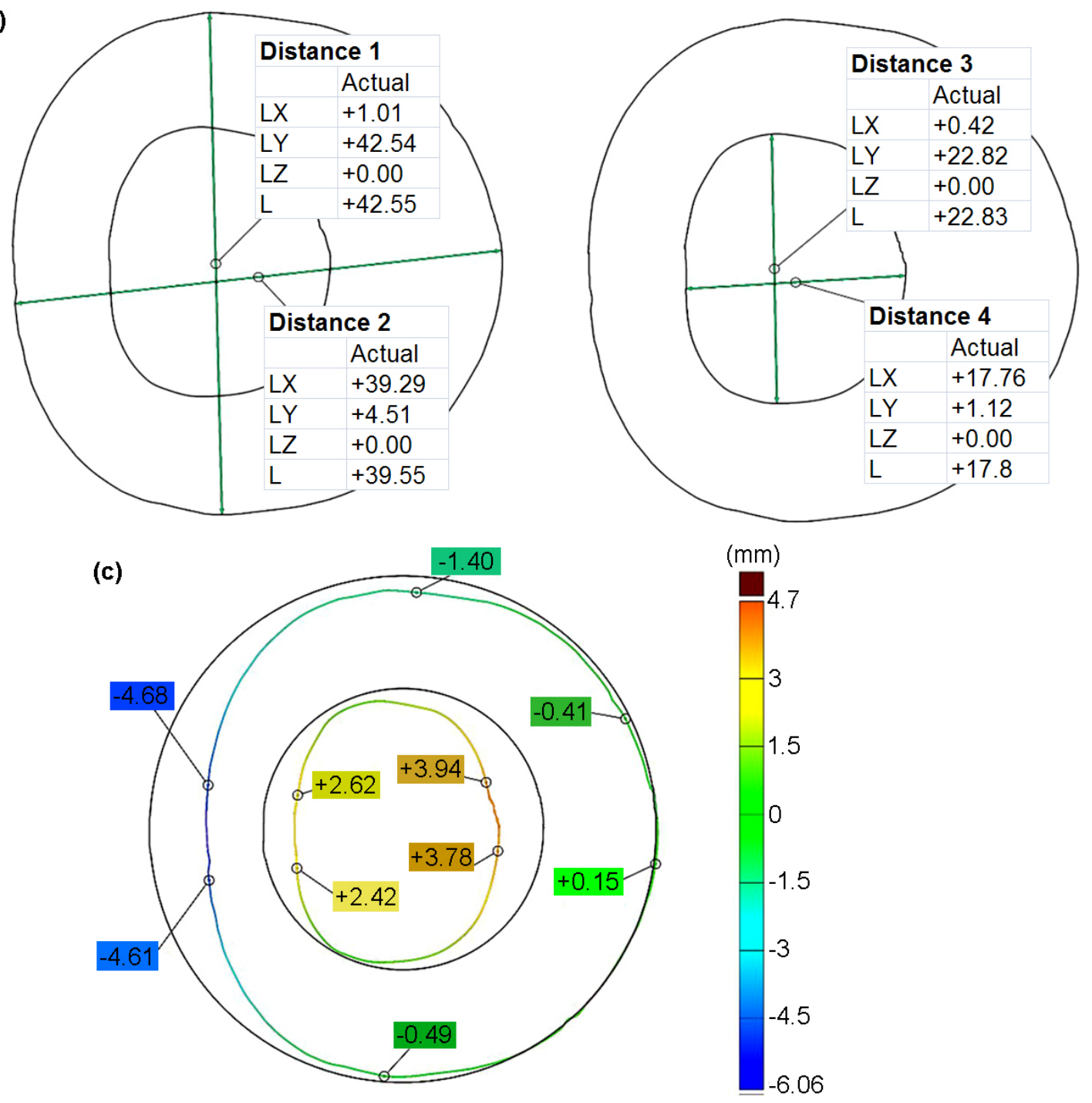

\section{Figure 4}

(a) The position of cuts on the part with defined bending radius 0.7D, (b) Outer (left) and inner (right) dimensions of Cut 4, (c) The course of deviations of the 0.7D bend againstthe CAD model in Cut 4. 

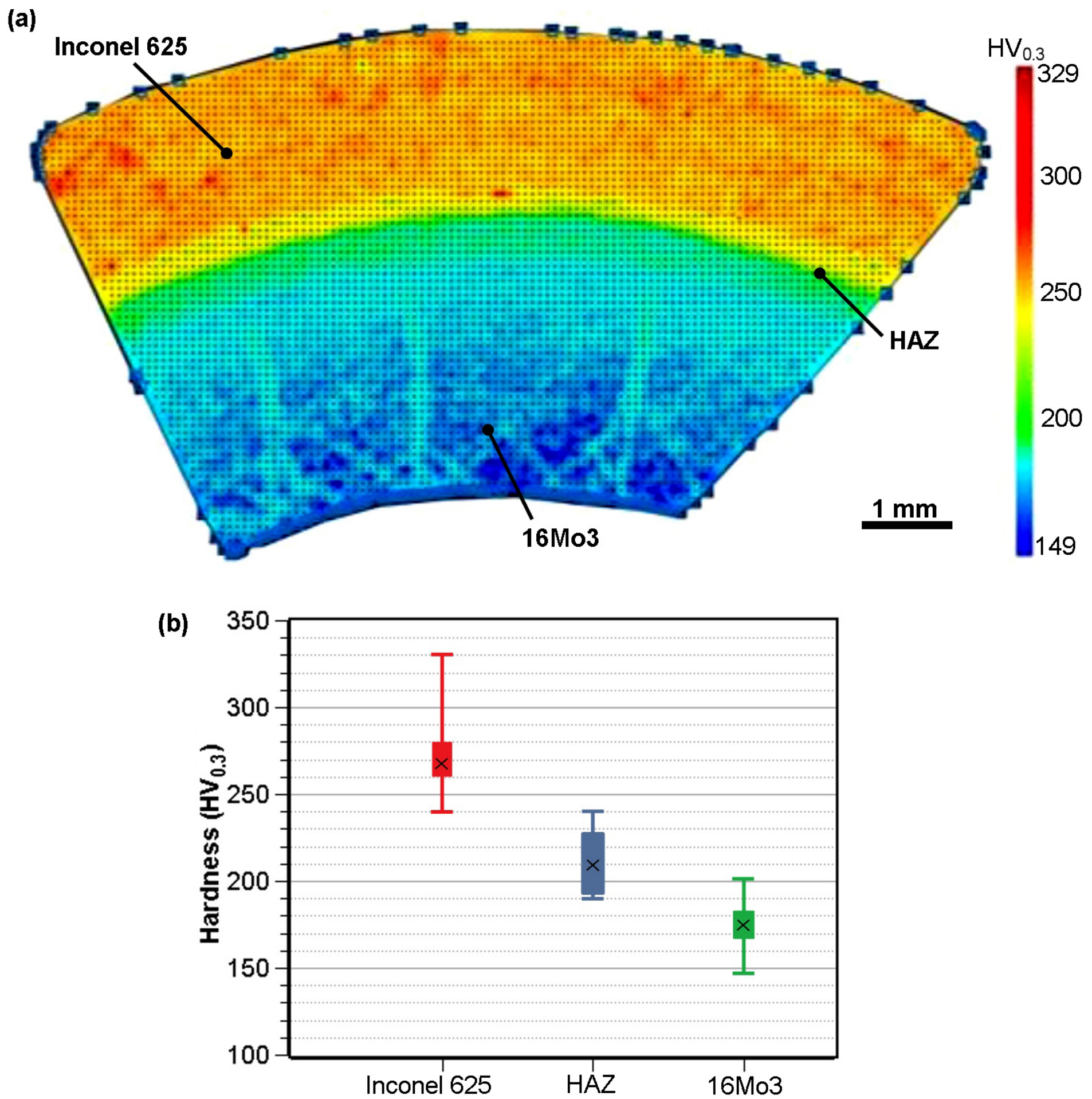

Figure 5

(a) the hardness map, (b) the boxplot of measured values from a map containing the maximum and minimum measured values in individual areas, the average value of hardness in the area (marked $\times$ ), as well as the standard deviation. 
(a)
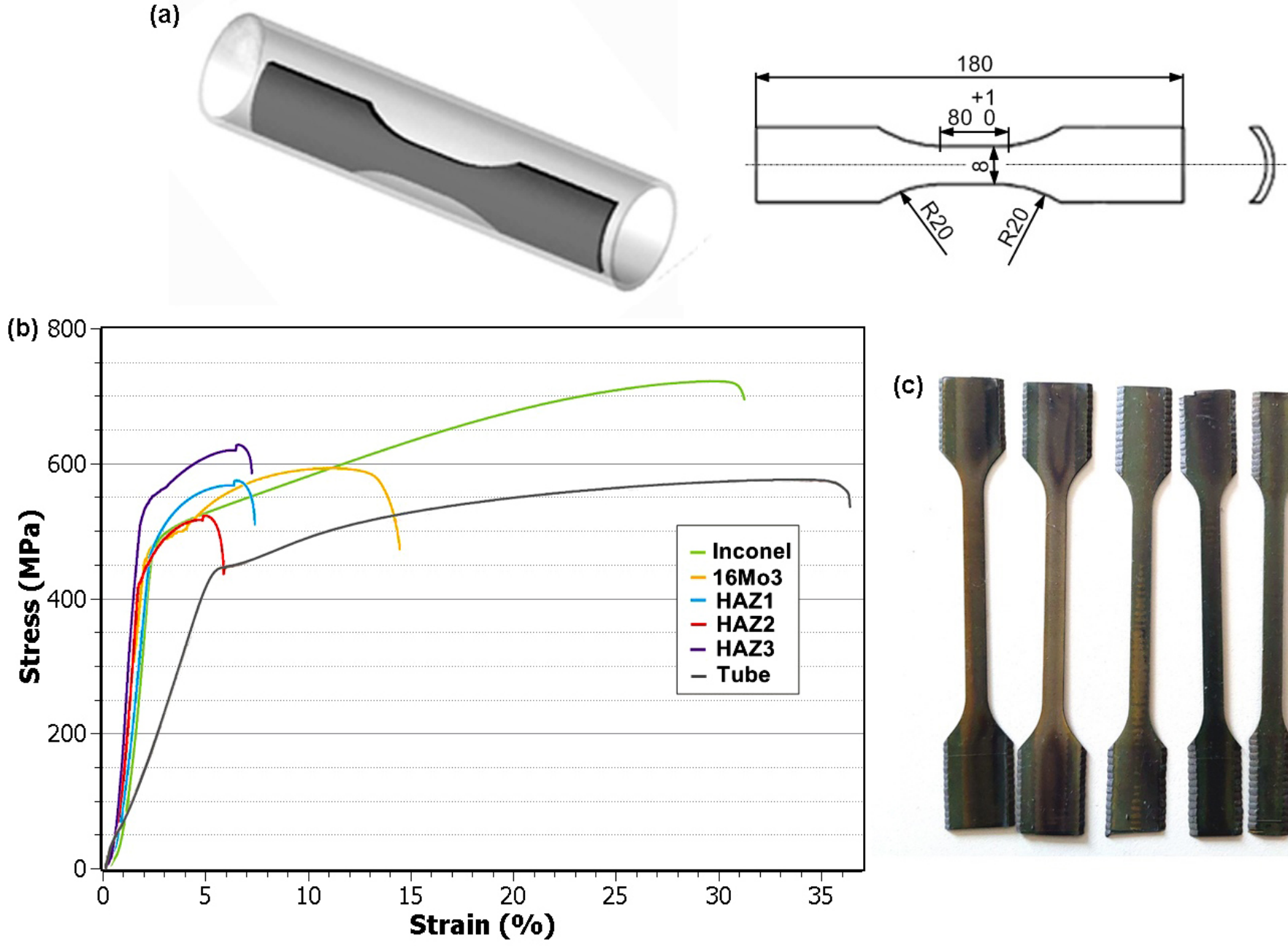

(c)

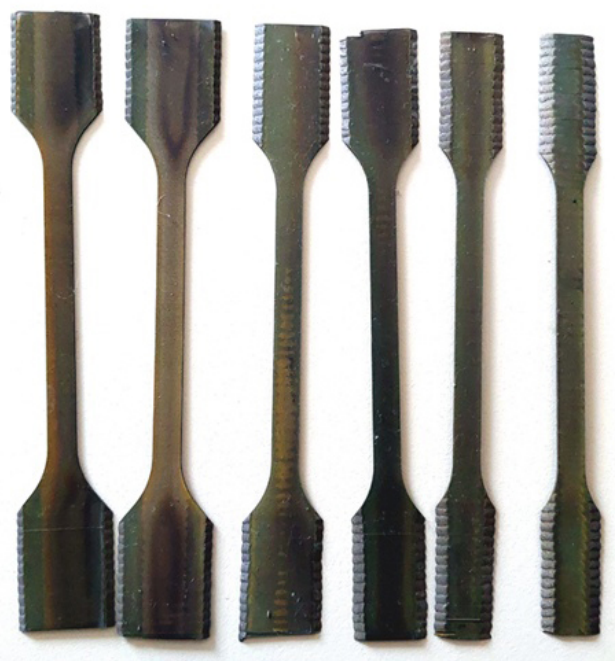

Figure 6

(a) a schematic diagram showing the sampling point of the test specimen and its sketch with dimensions; (b) The tensile stress-strain curves for each specimen, (c) produced test specimens before the test. 

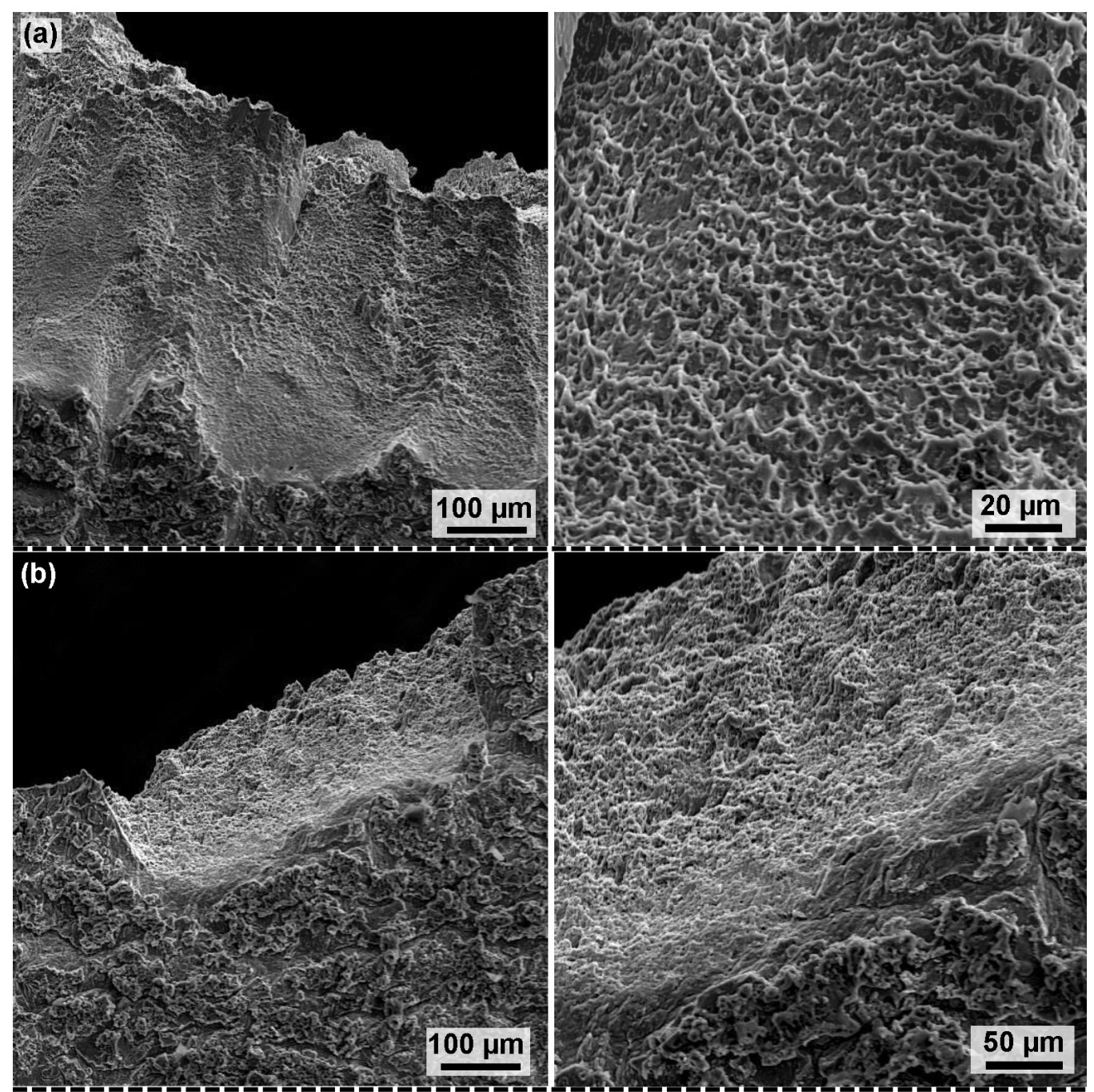

(c)
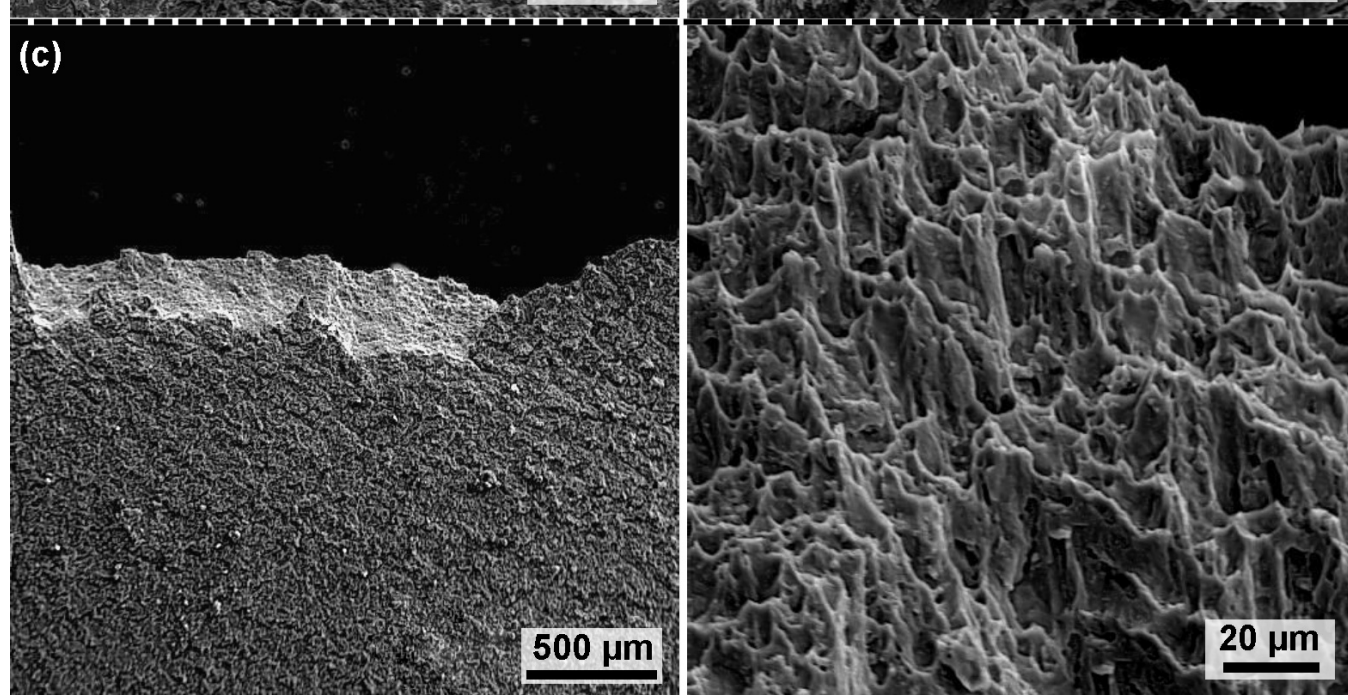

Figure 7

Fracture surfaces (REM) (a) Inconel 625, (b) HAZ3, (c) 16 Mo3 steel. 